\title{
Correspondence
}

\section{A simple technique for topical anaesthesia of the airway}

To the Editor:

We would like to report a simple technique for topical anaesthesia of the airway. It obviates the need for complicated equipment, and is well tolerated by the patient.

After administration of an antisialogogue, $8-10 \mathrm{ml}$ of $4 \%$ lidocaine are drawn up into a $20 \mathrm{ml}$ syringe, and then diluted by an equal volume of sterile water. Then the patient is asked to open his or her mouth, and extrude his or her tongue, which is grasped with a gauze pad. Very gentle traction is then applied, which prevents the patient from swallowing. Two to three $\mathrm{ml}$ of the solution is deposited at the back of the patient's tongue, and allowed to trickle backwards during deep breathing. This is repeated every 2-3 minutes. If mouth opening is limited, a 14 gauge cannula attached to the syringe facilitates the process. Fiberoptic bro ichoscopy and tracheal intubation can proceeed forthwith.

We have used this technique successfully is over 30 patients for anticipated difficult intubation, diagnostic bronchoscopy, and tracheal intubation in the presence of a fractured cervical spine.

\section{Donald Oxorn MD CM FRCPC \\ Department of Anaesthesia \\ Camp Hill Medical Centre \\ Halifax, Nova Scotia}

David Chung MD FFARCS FRCPC

Department of Anaesthesia

The Mississauga Hospital

Mississauga, Ontario

\section{Venous tolerance to etomidate in lipid emulsion or propylene glycol (hypnomidate)}

To the Editor:

The purpose of this study was to determine if the vehicle in which etomidate is administered affects the rate of local complications, i.e., pain on injection and venous sequelae.

In a randomized single-blind study, 100 patients were divided into two independent groups, of 50 each. They received etomidate, $0.3 \mathrm{mg} \cdot \mathrm{kg}^{-1}$ over $20 \mathrm{sec}$, either in a new formulation (group B), containing $20 \mathrm{mg}$ etomidate in $10 \mathrm{ml}$ of a lipid emulsion (Lipufundin ${ }^{\circledR}$ MCT 20 per cent) or the commercially available etomidate in 35 per cent propylene glycol (group A). Male and female patients aged 18-65 yrs, and of ASA physical states I-III, were eligible.

Each patient received lormetazepam I-2 mg orally 60 min before anaesthesia commenced. Care was taken to inject each preparation through a large bore cannula (17G) which was placed in a large forearm vein and removed ten minutes after the injection. The other drugs required for anaesthesia were given via a cannula in the other arm.

The induction of anaesthesia and its depth were assessed on the basis of the patients' behaviour and of the lid, corneal and pupillary reflexes. Circulatory function was monitored by blood pressure, pulse and ECG.

Following etomidate in propylene glycol, 36 per cent of the patients described the injection as painful. On the first postoperative day, 9 out of the 47 patients studied further had a phlebitis (tenderness on palpation of the vein) and three others a thrombosis (hardness of the vein). On the seventh day after operation a venous reaction was evident in 22 per cent of these patients. Two patients had a phlebitis (four per cent), five patients (ten per cent) had a thrombosis with obvious hardening of the vein, and four patients (eight per cent) had a thrombophlebitis (tender and hard vein) extending over several $\mathrm{cm}$.

There were no signs of local irritation after etomidate in lipid emulsion. The patients did not complain of any pain during the injection, and venous sequelae were not seen. The anaesthetic induction time (group A: $42.2 \mathrm{sec}$; group B: $41.1 \mathrm{sec}$ ) and loss of reflexes were nearly identical in both groups. Blood pressure and heart rate were stable and similar in both groups.

Two unpleasant side-effects of etomidate, pain on injection and postoperative thrombophlebitis can be abolished while retaining the excellent profile of actions. It is concluded that the lipid emulsion is the preferable vehicle for clinical use. ${ }^{1-3}$

A. Doenicke

A. Kugler

N. Vollmann

Institut für Anaesthesiologie der

Ludwig-Maximilian-Universität

Pettenkoferstraße 8a, D-8000 München 2 


\section{REFERENCES}

1 Doenicke A, Duka, $T$, Suttman $H$. Venous reactions following etomidate (letter). Br J Anacsth 1984; 56: 933.

2 Gran L, Bleie H, Jeppson R, Maartman-Moe H. Etomidat mit Intralipid. Eine Lösung zur schmerzfreicn injektion. Anacsthesist 1983; 32: 475-7.

3 Suttmann H, Doenicke A, Kugler J, Laub M. Eine neuc Zubereitung von Etomidat in LipidemulsionBioverfügbarkeit und Verträglichkcit. Anacsthesist 1989; 38: 421-3.

\section{Obstruction of a preformed armoured tracheostomy tube}

\section{To the Editor:}

Hazards associated with the use of armoured silicone tracheal tubes have been reviewed recently. ${ }^{\prime}$ We report a complication associated with the use of a preformed armoured tracheostomy tube which occurred during surgery.

A 65-yr-old woman (ASA physical class III) weight $61 \mathrm{~kg}$ was scheduled for tracheostomy, resection of the floor of the mouth and radical neck dissection. Following uneventful induction of anaesthesia, an $8.00 \mathrm{mmlD}$ cuffed PVC oral tracheal tube was positioned easily. A tracheostomy was performed and a $7.0 \mathrm{mmID}$ silicone cuffed preformed flexible tracheostomy tube (Laryngoflex Rüsch AG, West Germany) was positioned and bilateral breath sounds auscultated. Mechanical ventilation was commenced and peak airway pressure was $25 \mathrm{cmH}_{2} \mathrm{O}$. At the surgeon's request, the tube was not secured with suture or tape. Surgery proceeded uneventfully until $3 \frac{1}{2} \mathrm{hr}$ later when airway pressures were noted to be increasing. Over a period of ten minutes, peak airway pressure increased to $60 \mathrm{cmH}_{2} \mathrm{O}$. Manual ventilation was commenced. Breath sounds were checked and no wheezing was detected. A suction catheter was inserted into the trachea by the surgeons with some difficulty, and some blood-stained material was aspirated. However, airway pressures remained high and the surgeons were asked to replace the tube with a preformed red-rubber laryngectomy tube (Rüsch AG, West Germany). As the tube was withdrawn, it was noted to be sited only just within the lumen of the trachea, and the surgeon suggested that his team had inadvertently withdrawn the tube. When the new tube was positioned, peak airway pressure immediately returned to normal. No other problems ensued during the remainder of the anaesthetic.

Later, the tube and its cuff were inspected and found to be intact. The lumen was free form any obstructing material. The tube was then inserted into the barrel of a
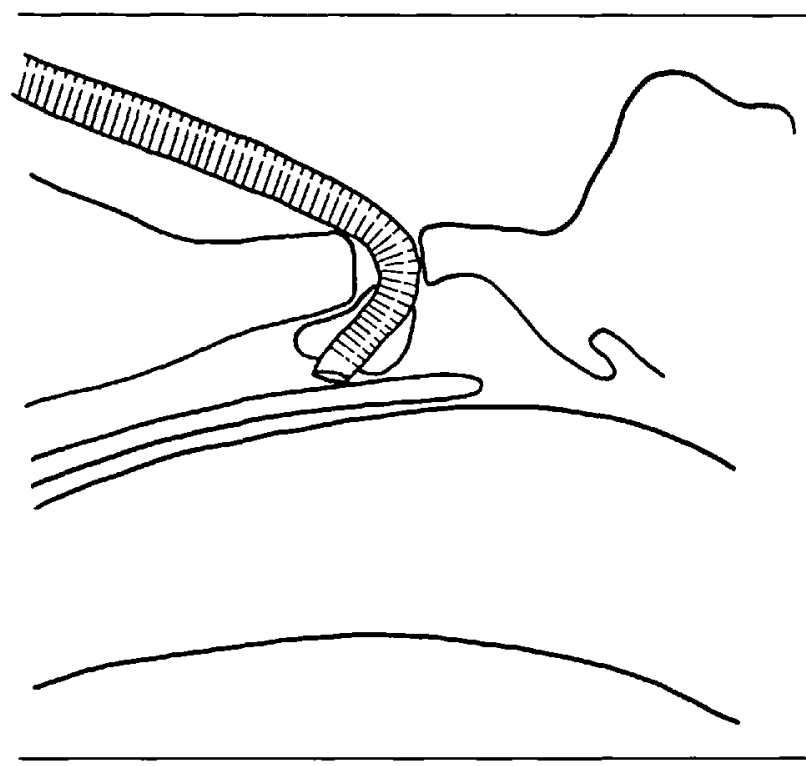

FIGURE 1. Diagram of a performed armoured tracheostomy tubc malpositioned against tracheal wall, resulting in obstruction.

$20 \mathrm{ml}$ syringe and the cuff inflated to prevent a leak. Gentle traction was then applied to the long axis of the tube and the bevel of the tube became abutted gainst the wall of the syringe. A diagrammatic representation of our proposed cause of the obstruction is shown in the Figure. The combination of soft cuff and short distance between the cuff and distal tip of the tube permits malpositioning when the tube is withdrawn. Methods to reduce the risk of obstruction of tracheal tubes include an angulated bevel or a Murphy eye. However, these modifications weaken the distal end of the tube and allow the tip to bend and cause obstruction. Further, inadvertent movement of the tube is more likely when it is not secured to the patient. Lack of markings on the tube gives no indication when a tube has been withdrawn inadvertently.

This incident illustrates again the benefits of replacing tracheal tubes when unexplained difficulties with ventilation occur, and emphasizes the important of adequate tube fixation.

Richard H Riley MB BS

Simon A. Mason

Catharine D Barber MB BS

Department of Anaesthesia

Royal Perth Hospital

Box X2213 GPO

Perth, WA 6001

Australia

\section{REFERENCE}

1 Wright PJ, Mundy JVB, Mansfield CJ. Obstruction of armoured tracheal tubes: casc report and discussion. Can J Anaesth 1988; 35: 195-7. 